\title{
Enforcing Federal Drug Laws in States Where Medical Marijuana Is Lawful
}

Lawrence O. Gostin

Georgetown University, gostin@law.georgetown.edu

James G. Hodge

Arizona State University Sandra Day O'Connor College of Law, james.hodge.1@asu.edu

Sarah A. Wetter

Arizona State University Sandra Day O'Connor College of Law, sarah.wetter@asu.edu

This paper can be downloaded free of charge from:

https://scholarship.law.georgetown.edu/facpub/2061

https://ssrn.com/abstract=3149857

Lawrence O. Gostin, James G. Hodge, Jr. \& Sarah A. Wetter, Enforcing Federal Drug Laws in States Where Medical Marijuana Is Lawful, 319 JAMA 1435-1436 (2018).

This open-access article is brought to you by the Georgetown Law Library. Posted with permission of the author. Follow this and additional works at: https://scholarship.law.georgetown.edu/facpub 


\section{Enforcing Federal Drug Laws in States Where Medical Marijuana Is Lawful}

\begin{tabular}{l}
\hline Lawrence O. Gostin, \\
JD \\
O'Neill Institute for \\
National and Global \\
Health Law, \\
Georgetown University \\
Law Center, \\
Washington, DC. \\
\hline James G. Hodge Jr, JD, \\
LLM \\
Sandra Day O'Connor \\
College of Law, Arizona \\
State University, \\
Phoenix. \\
\hline Sarah A. Wetter, JD \\
Sandra Day O'Connor \\
College of Law, Arizona \\
State University, \\
Phoenix. \\
\\
$\leftarrow$ \\
Viewpoint page 1433 \\
+ \\
Supplemental \\
content
\end{tabular}

content

\author{
Corresponding \\ Author: Lawrence $\mathrm{O}$ \\ Gostin, JD, O'Neill \\ Institute for National \\ and Global Health Law, \\ Georgetown \\ University Law Center, \\ 600 New Jersey Ave \\ NW, Washington, DC \\ 20001 (gostin@law \\ .georgetown.edu).
}

On January 4, 2018, Attorney General Jeff Sessions issued a memorandum immediately rescinding the Obama Administration's long-standing guidance limiting federal enforcement of medical marijuana. ${ }^{1}$ Federal law creates harsh penalties for the cultivation, distribution, and possession of marijuana, which Sessions deemed a "dangerous drug" and a "serious crime." The memorandum places physicians and patients at risk of arrest and prosecution in 29 states and the District of Columbia that have legalized medical use of marijuana (eTable in the Supplement).

This Department of Justice (DOJ) guidance came at a time of increasing acceptance, accessibility, and use of cannabis and its derivatives. According to a 2015 nationwide survey, an estimated 22.2 million individuals in the United States aged 12 years or older reported cannabis use in the past 30 days; $90 \%$ said their primary use was recreational, with $10 \%$ solely for medical purposes; $36 \%$ reported mixed medical and recreational use. ${ }^{2}$ A 2017 national poll found that $61 \%$ of respondents support legalization of marijuana and $71 \%$ oppose federal enforcement. ${ }^{3}$ In 2016, an estimated

\section{On an issue as consequential as marijuana, the nation needs consistent legal norms based on the best available scientific evidence.}

1.2 million adults accessed medicinal marijuana through state-licensed dispensaries or home cultivation. ${ }^{4}$

\section{The Case for Research}

Marijuana is classified as a Schedule I drug (like heroin) under the Controlled Substances Act (CSA) of 1970, with high potential for abuse and no recognized or approved medical uses. The aggregated evidence of marijuana's medical benefits, harms, and potential role as a gateway to more serious drug dependency is uncertain and incomplete.

The National Academies found evidence that patients treated with cannabis or cannabinoids experienced significant pain relief. Short-term use of oral cannabinoids improved reported symptoms of multiple sclerosis-related muscle spasms. Oral cannabinoids can prevent or ameliorate chemotherapy-induced nausea and vomiting. ${ }^{5}$ However, evidence of effectiveness is lacking for diverse conditions for which cannabis is prescribed, including cancers, glaucoma, irritable bowel syndrome, epilepsy, and dystonia. For these conditions, prescribing physicians often rely on limited clinical and anecdotal evidence. $^{6}$
Like many controlled substances, marijuana has significant adverse effects. It can induce dizziness, panic attacks, nausea, vomiting, hallucinations, and temporary learning and memory impairments. Regular use increases risks of substance dependency and smoking-induced respiratory symptoms. It also increases injury risks, including through vehicular collisions.

Certain groups could be at increased risk, including children, adolescents, and pregnant women. Habitual marijuana smoking at a young age can limit educational and employment opportunities. Newborns of women who smoke during pregnancy may have low birth weights or develop longer-term cognitive impairments. Ingestion of marijuana-infused "edibles" by children has led to life-threatening poisonings. After implementation of legal recreational use in Colorado in 2014 , there was a $34 \%$ increase in hospitalizations of children related to marijuana. ${ }^{7}$

Despite the imperative for better evidence, marijuana's Schedule I status and absence of US Food and Drug Administration approval pose major research barriers. Research funding is limited. Highquality cannabis for research is scarce. No standards have been set for the purity and potency of marijuana, resulting in varied quality and dosage. The amount of $\Delta^{9}$-tetrahydrocannabinol (THC), the principal psychoactive component, ranges extensively. Contaminants in marijuana, including fungi or pesticides, can be toxic.

Law, Policy, and Politics

Beginning with California's Compassionate Use Act in 1996, states have reduced punitive sanctions for marijuana use. Nearly all states allow some medicinal uses of THC (classified separately under the CSA). States authorizing medical marijuana delineate conditions for which it can be prescribed. California's physicians can prescribe marijuana for any "chronic or persistent medical symptom" that limits patients' daily life activities or seriously impairs physical or mental health. Several states limit access through an authorized dispensary, while others (eg, Colorado) permit home cultivation (eTable in the Supplement).

Legal challenges to state marijuana laws have proved largely unsuccessful, including groups seeking to withdraw medical marijuana from ballot referendums or to wield zoning and land-use laws to constrain cultivation of marijuana and placement of dispensaries. Workplace "zerotolerance" policies also pose employment risks for marijuana users.

In Gonzales $v$ Raich, ${ }^{8}$ the Supreme Court held that the DOJ can enforce federal drug laws even for purely 
intrastate manufacture and possession of medical marijuana. The CSA preemption applies only if federal and state laws "cannot consistently stand together." ${ }^{5}$ State legalization of medical marijuana arguably can coexist with federal law, but the DOJ's new guidance places physicians at risk of liability to which courts may defer.

The DOJ overturned the Obama Administration's guidance centered on prosecution of large-scale marijuana production facilities ${ }^{9}$ with goals of preventing minors' access to marijuana, illegal sales, covert trafficking, and intoxicated driving. Since 2016, Congress has supported state sovereignty, enacting the Rohrabacher-Blumenauer Amendment, which prohibits use of federal funding to impede state medical marijuana laws. Sessions asked Congress to remove the rider from the 2018 spending bill despite bipartisan support.

The net effect of the DOJ's 2018 memorandum is unclear. Physicians prescribing and patients using cannabis lawfully under state statutes could be subject to federal prosecution. Still, prosecutors have wide discretion and limited resources. Many will not bring charges against individuals who rely on state law. Several US attorneys have already announced their intention to follow Obama-era guidance. State legislators and policy makers in medical marijuanajurisdictions have pledged to use all legal and political means to defend states' rights.

Toward Rational Medical Marijuana Policies

Although public opinion and state action have trended strongly toward permitting use of marijuana, especially for medical purposes, controversy continues to exist. The specter of federal prosecution could refrain physicians, patients, and dispensaries from providing marijuana in states where the drug is lawful and dissuade additional jurisdictions from legalizing marijuana. Public policy formed and implemented in the context of inconsistent federal and state laws, unpredictable legal enforcement, and insufficient scientific evidence is unsustainable. Rational policies should follow a 3-pronged agenda.

\section{A Solid Research Foundation}

Sound policy requires a strong evidence base. Scientific studies could quell ongoing disagreements about marijuana's medical effectiveness, harms, and status as a gateway drug. Yet limited funding and restrictive access to uniformly high-quality cannabis have sharply curtailed longitudinal studies on a drug already in wide use. Physicians require rigorous evidence to inform prescribing practices and counseling of patients. At present, wide regional variations in prescribing practices exist, and patients do not have access to consistently high-quality, uncontaminated cannabis-where the purity, potency, and dosage can be ensured. Health officials, moreover, rarely conduct careful surveillance of marijuana use incidence, prevalence, and outcomes. Public policy on a potentially hazardous psychotropic drug is difficult when shortand long-term effects across populations are underreported, insufficiently studied, and poorly funded.

\section{A Harmonized Legal Environment}

Substantial variability of legal approaches to marijuana use exists across jurisdictions and between states and the federal government. Individuals in certain jurisdictions can lawfully access marijuana for medical use, recreational use, or both, whereas individuals in other jurisdictions cannot do so.

Conditions under which physicians can prescribe (or patients can access) marijuana fluctuate extensively. Federal law is inconsistent with policy in virtually all states. The CSA should be revised to operate harmoniously with prevailing state law. Model legislation for medical use of marijuana, based on scientific evidence, could help reconcile activities across jurisdictions.

\section{Federal Law Enforcement Respectful of States' Sovereignty}

Under US constitutional design, states and localities are laboratories for innovation, with state sovereignty and local home rule respected and preserved. This requires federal prosecutorial discretion to hew to the legal environment of states that have legalized marijuana use. Respecting marijuana laws is essential in states where cannabis is prescribed and used for medical purposes. On an issue as consequential as marijuana, the nation needs consistent legal norms based on the best available scientific evidence.

\section{ARTICLE INFORMATION}

Published Online: March 26, 2018

doi:10.1001/jama.2018.1083

Conflict of Interest Disclosures: All authors have completed and submitted the ICMJE Form for Disclosure of Potential Conflicts of Interest and none were reported.

\section{REFERENCES}

1. Memorandum for All US Attorneys: Marijuana Enforcement. Washington, DC: Office of the Attorney General Jeffrey B. Sessions; January 4, 2018.

2. Center for Behavioral Health Statistics and Quality. Behavioral Health Trends in the United States: Results From the 2014 National Survey on
Drug Use and Health. Washington, DC: US Dept of Health and Human Services; 2015

3. De Pinto J, Backus F, Khanna K, Salvanto A. Marijuana legalization support at all-time high. April 20, 2017. https://www.cbsnews.com/news /support-for-marijuana-legalization-at-all-time-high /. Accessed March 16, 2018.

4. ProCon. Number of legal medical marijuana patients. March 3, 2016. https://medicalmarijuana .procon.org/view.resource.php?resourcelD =005889. Accessed March 16, 2018.

5. National Academies of Sciences, Engineering, and Medicine. The Health Effects of Cannabis and Cannabinoids: The Current State of Evidence and Recommendations for Research. Washington, DC: National Academies Press; 2017.
6. Whiting PF, Wolff RF, Deshpande S, et al. Cannabinoids for medical use: a systematic review and meta-analysis. JAMA. 2015;313(24):2456-2473.

7. Wang GS, Le Lait MC, Deakyne SJ, Bronstein AC, Bajaj L, Roosevelt G. Unintentional pediatric exposures to marijuana in Colorado, 2009-2015. JAMA Pediatr. 2016;170(9):e160971.

8. Gonzales v Raich, 545 US 1 (2005).

9. Memorandum for US Attorneys: Guidance Regarding the Ogden Memo in Jurisdictions Seeking to Authorize Marijuana for Medical Use. Washington, DC: Office of the Deputy Attorney General James M. Cole; June 29, 2011. 